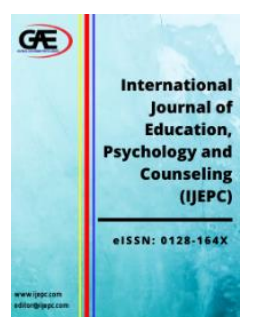

\author{
International Journal of Education, \\ Psychology and Counselling (IJEPC) \\ Journal Website: http://ijepc.com/ \\ eISSN: 0128-164X
}

\title{
SEX DIFFERENCES IN INTELLECTUAL ABILITY AMONG PRESCHOOL CHILDREN IN PUTRAJAYA
}

\author{
Tang Lee Foong ${ }^{1}$, Zarinah Arshat ${ }^{2}$, Rumaya Juhari ${ }^{3}$
}

1 Faculty of Human Ecology, Universiti Putra Malaysia (UPM), Malaysia

Email: tangleefoong@gmail.com

2 Faculty of Human Ecology, Universiti Putra Malaysia (UPM), Malaysia

Email: zarinah_upm@upm.edu.my

3 Faculty of Human Ecology, Universiti Putra Malaysia (UPM), Malaysia

Email: rumaya@upm.edu.my

Article Info:
Article history:
Received date: 13.11 .2019
Revised date: 12.12 .2019
Accepted date: 23.01 .2020
Published date: 15.03 .2020
To cite this document:
Tang, L. F., Arshat, Z., \& Juhari, R.
(2020). Sex Differences in
Intellectual Ability among Preschool
Children in Putrajaya. International
Journal of Education, Psychology and
Counseling, 5 (34), 40-59.

DOI: $10.35631 /$ IJEPC.534004.

\begin{abstract}
:
Past research has shown that children with the higher intellectual ability or intelligence quotient (IQ) were found less likely to be held back a grade in their schooling years and were less likely to be rejected by their peers or to have very few friends. The present study was conducted to determine the sex differences in intellectual ability among preschool children in Putrajaya. The research sample of 234 preschool children aged 6 from 16 private preschools in Putrajaya Malaysia was selected by using a cluster sampling technique. Preschool children's intellectual ability was measured by using The DrawingA-Person Intellectual Ability Test for Children, Adolescents, and Adults (DAP: IQ; Reynolds \& Hickman, 2004). Higher scoring on the DAP: IQ signified higher IQ level which represents the higher intellectual ability of the preschool children. Results showed that there was a significant difference in intellectual ability, where preschool girls were found to have higher intellectual ability scores than boys. The study concluded that preschool boys and girls were different in their biology and social development which may cause differences in their intellectual ability level. The finding implied the need for more attention from the preschool setting to further improve their academic planning in order to enhance both preschool boys and girl's learning and development.
\end{abstract}

\section{Keywords:}

Sex Differences, Intellectual Ability, Preschool Children, Parents 


\section{Introduction}

Children grow and learn through exploration using their thinking skills to make sense of their environment and the world around them, sort out solutions for the problems they encountered with and understand what happens around them through their intellectual abilities. Intellectual ability pertains to how children think and understand things (Bukatko \& Daehler, 2012). Psychologists defined intellectual ability as an individual's aptitude of mental processes including abstract thought, reasoning, comprehension, knowledge acquisition, adaptation and problem solving (Flavell, 1999).

Furthermore, intellectual ability has likewise been found to contribute to individual's later developmental outcomes and future life (Bukatko \& Daehler, 2012), and individual's positive educational outcomes, such as overall education attainment, school performance, and higher rate of university completion (Mark, 2013). In addition, intellectual ability was found to be a very important variable in the economics field in determining individuals' productivity and earning in the human capital models (Heckman \& Mosso, 2014), where early childhood intellectual ability has a long-term effect on individuals' socioeconomic status during adulthood (De Graaf, De Graaf \& Kraaykamp, 2000); which can shaped their well-being throughout the course of life (Huang, Xie, \& Xu, 2015). Moreover, intellectual ability also strengthens an individual's inclination towards a more ethical lifestyle and a greater appreciation of the quality of the education, security, work, future, and individualised love (Rindermann, Sailer, \& Thompson, 2009).

Early research showed that children with a higher intellectual ability are less likely to have very few friends or get rejected by their peers (Wentzel \& Erdley, 1993), and are less likely to be left behind in their grade level during their schooling years (Safer, 1986). Recent research showed that preschool children's intellectual ability is considered among the most essential predictors of academic performance for the rest of their lives (Nisbett, Aronson, Dickens, Flynn, Halpern, \& Turkheimer, 2012). As a consequence, children's intellectual ability is considered an important domain that correlates with their school readiness (Powell, 2010). Children with low intellectual ability and low school readiness when transitioning from preschool to primary education might not be able to catch up with the school syllabus and might be left far behind in the class learning progression. This might affect their academic performance and their interest in learning, which, in turn, could make them fall below the average and be categorised as underachievers. In view of this, parents and teachers should take children's intellectual development seriously. Hence, to prevent negative child outcomes, their intellectual abilities must be enriched.

On the other hand, sex differences in intellectual ability have captured the interest of social scientists, psychologist and educators. Differences between boys and girls exist in various areas of development (including intellectual ability), wherein girls are regarded as having superior progress than boys do (Bruce, 2006). In contrast, boys have been observed to have slightly higher means scores on mathematical reasoning tests compared to girls (Hyde, Fennema, \& Lamon, 1990; Feingold, 1988). Similarly, boys have been found to have better quantitative skills and score higher in mathematics relative to girls; whereas, girls displayed higher scores in English than their male counterparts (Calvin, Fernandes, Smith, Visscher, \& Deary, 2010). Within the Malaysia research focus, studies relating to sex differences among preschool children's intellectual ability have been relatively lesser compared to other western countries. There is a need to examine the intellectual ability amongst preschool children, especially the 6-year-olds, who need to pass through the transition from preschool to primary education in 
order to specify and provide necessary support for those who need so. This is not be taken lightly because preschool children's intellectual ability will bring effect on their primary school academic performance and development outcomes.

\section{Literature Review}

Since the 1980s, a lot of research had been done to reach to an essential conclusion on cognitive gender differences. As a consequence, two common methods were used which included of the (a) analysis from standardised test norms (e.g., Feingold, 1988; Stanley, Benbow, Brody, Dauber, \& Lupkowski, 1991) and the (b) review of meta-analytic report (e.g., Hyde, Fennema, \& Lamon, 1990; Stanley et al., 1991). However, studies applying these two common methods have discovered two different conclusions of average sex differences in the general population. Firstly, the standardised test norm analysis revealed that females scored higher than males in the test of perceptual speed and language usage. Secondly, the meta-analytic review report revealed that males scored higher than females in the test of mechanical reasoning, mental rotation and general knowledge; and in the test of memory span, verbal ability, and general abstract, there was no notable sex differences for both males and females (e.g., Kimball, 1989; Feingold, 1988;).

In recent years, meta-analyses study done by Hyde (2016) on children and adults, found that females and males performed equally in mathematics assessments; and that males and females were quite similar on most but not all psychological variables. In addition, the studies on cognitive sex differences are still considered controversial. Pezzuti and Orsini (2016) investigation using Wechsler Intelligence Scale for Children - Forth Edition (WISC-IV) to determine the sex differences proved that even though females were found to score higher in Processing Speed and males scored higher in Verbal Comprehension, there were no significant differences between males and females in their General Intelligence, Working Memory, and Perceptual Reasoning.

Sex differences in intellectual ability have been viewed as a global concern for the past decades. Quite a number of stereotypical cases have been reported happened on females, especially adult women who work in the professional fields such as chemistry, medicine, and engineering. Even children have been educated since they were young that boys and girls are different in their cognitive ability, where boys are always categorised into the smart and clever group (Bian, Leslie \& Cimpian, 2017). Besides, boys have been regarded as more vulnerable, have more demands on parental contact and are more reactive emotionally to unpleasant stimuli than girls do. Moreover, boys' outcomes are more influenced by parenting than girls' according to the work by Harewood, Vallotton, and Brophy-herb (2016).

Sex differences may contribute to certain influence on a child's development progress. Some researchers supported that girls have higher level of intellectual ability than boys and performed better than boys. While Bruce (2006) concluded that girls tend to have superior progress than boys in various areas of development which included of intellectual ability. It was proved that girls tend to score higher than boys on both verbal and non-verbal abilities by age of 2 to 4 , where girls have overall faster development in intellectual ability during the pre-pubertal stage and advanced over the boys in the first 4-years of life in most cognitive domains (Toivainen, Papageorgiou, Tosto \& Kovas, 2017). It is supported by Kleinfeld (1998) argument who suggested that girls are achieving higher rate than boys, less likely to be diagnosed as slow learner or dyslexic as girls tends to get higher (average) grades in all subjects in school, managed to obtain higher scores on most achievement test in the early elementary school years. 
In contrary, there were some studies which found that boys perform better than girls. These studies (e.g., Feingold, 1988; Hyde et al., 1990) discovered that boys had slightly higher mean scores on mathematical reasoning tests compared to girls. Annual psychology reviews conducted by Deaux (1985) to determine sex differences in intellectual ability using three areas of measurements which namely, verbal ability, mathematical ability, and spatial ability, concluded that boys were more superior than girls in spatial ability and mathematical performance, but the opposite was true in terms of verbal ability. This was supported by a study done by Hedges and Friedman (1993) which revealed that males outperformed females on mathematical tests, mechanical tests, and all the ability tests, but not on those related to language, clerical and spelling ability. This can be explained by Ankey (1992) statement cited in Colom, Juan-Espinosa, Abad, and García (2000) that brain size is positively correlated with IQ, where on average males were found to have larger brains than females; and therefore males were expected to have a higher average level of IQ than females.

Furthermore, young boys and girls were found to have different social skills or social preference. For instance, in a preschool classroom setting, boys and girls would socialise differently, that is, girls preferred a smaller group interaction and were more sedentary, while boys preferred a larger group interaction and a rough-and-tumble play (Bjorklund \& Blasi, 2012). An investigation done by Moller, Forbes-Jones, Hightower and Friedman (2008) to examine the relationship between preschool children's sex composition and developmental changes by employing a multilevel modelling approach revealed that sex composition had no effects at the classroom-level and did not influence girls' development. However, if a classroom had more boys, then there was especially worse development (Moller, Forbes-Jones, Hightower, \& Friedman, 2008). On the other hand, study done by Strand, Deary and Smith (2006) that examined intellectual abilities for UK sample of over 320,000 school pupils aged between 11 and 12, found that boys tend to perform both lowest and highest on their reasoning abilities, which might cause stereotyping boys as low achievers in academic performance and development.

Since the common sex stereotype is related to a high level of intellectual ability, being genius and brilliant were more related to men than to women. Hence, women are under-reprepresented in the aspect of intelligence and are even discouraged from further pursuit in many prestigious careers like men (Bian, Leslie, \& Cimpian, 2017). In fact, these sex stereotypes indeed influence younger generation's interest. A study carried out by Bian, Leslie, and Cimpian to examine sex stereotypes found that intellectual ability emerged in children's early years and further influenced their interests. Results revealed that the 6-year-old girls believed that boys are "really, really smart" and they start to avoid activities which are said to be for children who are "really, really smart" (Bian et al., 2017). In addition, the finding suggested that the gender notions or sex differences of brilliance are acquired in the early years of childhood and this brought about an immediate effect on children's interests (Bian et al., 2017).

\section{Methodology}

\section{Sample}

The sample for the present study consisted the selected private preschool children in Putrajaya and their biological mothers. The study sampled the 6-year-old preschool children and their mean age was 6.4 years. The cluster sampling method was utilised to select the respondents for the study. The final sample size in this study was 234 six-year-old preschool children. All $(100 \%)$ of the respondents were Malay. There were $106(45.3 \%)$ girls and $128(54.7 \%)$ boys 
who participated in the present study with the mean age of 6.4 years old (S.D. $=0.3$, Min. $=$ 5.9, Max. =6.9).

\section{Measurements}

The Drawing-A-Person Intellectual Ability Test for Children, Adolescents, and Adults (DAP:IQ; Reynolds \& Hickman, 2004) was employed to measure the preschool children's intellectual ability. This 23-criteria scale has a well-established norm for respondents aged 4 to 89 years old with reliability and validity tests showed that the alpha coefficients differed, from .74 at age 4 to .87 at age 30-39, and a mean and median values of .82 (Reynolds \& Hickman, 2004). The 23 criteria scoring in the DAP:IQ is based on the item being rated, is either " 0 to 1 point, 0 to 2 points, 0 to 3 points, and 0 to 4 points" (Reynolds \& Hickman, 2004). The drawing is not time-bound, yet, adult and child examinees usually finish their drawings within 5 minutes (Reynolds \& Hickman, 2004). After the examinees completed the drawing, their grade levels were measured by converting them into numerical form for statistical analysis using SPSS software.

\section{Analysis}

The data analysis was conducted by using the Statistical Package for the Social Science (SPSS), version 20. The exploratory data analysis (EDA) was conducted to test on the normality and linearity of the data. Descriptive analysis was used to describe the independent and dependent variables in the study. Independent-sample t-test was conducted to compare sex differences in the intellectual ability levels of preschool male and female child respondents.

\section{Results}

\section{Background of the Respondents}

Table 1 presents the background of the preschool children. Most of the mother respondents were working mothers, where majority of the preschool children $(n=200 ; 85.5 \%)$ stayed in day care even after school, and only a few of them $(n=34 ; 14.5 \%)$ were fetched home by their respective mothers who were homemakers. Almost all $(\mathrm{n}=226 ; 96.6 \%)$ of the child respondents stayed with both their biological parents, a few of them $(n=5 ; 2.1 \%)$ stayed with their mother, and a minority $(n=3 ; 1.3 \%)$ of them stayed at other settings or places. Since the working mothers had different working hours, child respondents had different duration of daily time spent with their mothers after work. There were 70 children (30\%) who spent 1 to 5 hours per day with their mothers after work, and some of them $(n=90 ; 38.5 \%)$ spent between 6 to 10 hours with their mothers after work. Moreover, there were 55 children (23.5\%), whose mothers worked part-time, managed to spend about 11 to 15 hours with their moms at home. In addition, there were only 19 children (8\%) who spent more than 16 hours per day with their mothers (homemaker or retiree) at home. Moreover, slightly half $(\mathrm{n}=137 ; 58.5 \%)$ of these preschool children were the eldest or the only child in the family, while the rest of $41.5 \%(\mathrm{n}=$ 97) were the later-born children.

Table 1: Background of the Preschool Children $(\mathrm{N}=234)$

\begin{tabular}{ccc}
\hline Variables & N \\
\hline
\end{tabular}

\section{After school arrangement}

Stayed in day care after school 


\section{Living arrangement}

Stayed with both their biological parents

Stayed with mother only

Stayed at other settings or places

$3 \quad 1.3$

\section{Daily time spent with mother}

1 to 5 hours

$70 \quad 30.0$

6 to 10 hours

$90 \quad 38.5$

11 to 15 hours

$55 \quad 23.5$

$\geq 16$ hours

\section{Birth order of the Child}

First born or the only child

\section{Child's Intellectual Ability}

Table 2 present the intellectual ability level of the preschool children. The preschool children's intellectual ability scores ranged in between 75 to 150 , a standard deviation of 13.98, and with a mean score of 115 which indicating high average IQ level.

\section{Table 2: Intellectual Ability of Preschool Children ( $\mathrm{N}=234)$}

\begin{tabular}{lcc}
\hline & n & \% \\
\hline Very superior (>130) & 26 & 11.1 \\
Superior (120-129) & 73 & 31.2 \\
High average (110-119) & 55 & 23.5 \\
Average (90-109) & 68 & 29.1 \\
Below average (80-89) & 11 & 4.7 \\
Mildly impaired (70-79) & 1 & 0.4 \\
Mean = 115; S.D. $=13.98$ & & \\
Min. =75; Max. $=150$ & & \\
\end{tabular}

Note: Min $=$ Minimum, Max $=$ Maximum, SD = Standard Deviation

While one-third of the preschool children $(n=73,31.2 \%)$ scored on the superior (120-129) IQ level, slightly more than half (52.6\%) of them got an average (90-109) and high average (110119) IQ scores. In contrast, there were only twenty-six (11.1\%) of the preschool children had a superior IQ level (>130), eleven (4.7\%) scored between 80 to 89 (below average), and only $1(0.4 \%)$ obtained an IQ score of 70 to 79.

Sex Differences in the Intellectual Ability of Preschool Children.

An independent-sample t-test was used to compare the mean scores of intellectual abilities between male and female preschool child. According to Pallant (2010), a value in Sig. (2tailed) column that is equal or less than .05 indicates a significant difference in the mean scores of the dependent variable for each two groups. 
Referring to Table 3, this study found a significant difference in mean scores of intellectual abilities between preschool boys and girls $(\mathrm{t}=-2.757, \mathrm{p}<.05)$. Preschool girls (mean $=117.68$, S.D. $=11.99$ ) had a higher intellectual ability mean score compared to preschool boys (mean $=112.69$, S.D. $=15.11$ ). The finding is consistent with Bruce (2006) study which proved that differences exist for boys and girls in various areas of development, where girls are known to have a more superior progress than boys do. It was also supported by investigation done by Toivainen, Papageorgiou, Tosto and Kovas (2017), where it was proved that girls have overall faster development in intellectual ability during the pre-pubertal stage and advanced over boys in most cognitive domains. In addition, girls were found not only achieving higher rate than boys, they were less likely to be diagnosed as dyslexic and managed to obtain higher scores on most achievement test in the early elementary school years (Kleinfeld,1998).

However, the present study was found to be contrary with other studies. Bian, Leslie, and Cimpian (2017) demonstrated that sex differences in brilliance acquired during early childhood years indeed endorsed and influenced younger generation's interest, where the 6-year-old girls believed that boys are "really, really smart" and tend to avoid engaging in activities that are for those who are "really, really smart". The result also was contrary to the finding of Deaux (1985) which showed that boys were more superior than girls in mathematical performance and spatial ability, and inconsistent with Hedges and Friedman (1993) study which revealed that males outperformed females on mathematical and mechanical test.

Table 3: Independent-sample t-test of Child Sex and Intellectual Ability (N=234)

\begin{tabular}{lccccc}
\hline & $\mathrm{n}$ & Mean Score & S.D. & t-value & p \\
\hline Boys & 128 & 112.69 & 15.11 & -2.757 & .010 \\
Girls & 106 & 117.68 & 11.99 & & \\
\hline
\end{tabular}

Note: $\mathrm{p}<.05, \mathrm{SD}=$ Standard Deviation

\section{Discussion and Conclusion}

The main objective of the present study was to compare the differences in intellectual ability between preschool boys and girls in Putrajaya, Malaysia. Results showed that preschool girls obtained higher intellectual ability scores than preschool boys, and this indicated that girls have superior progress than boys do in the preschool settings. Overall, there are differences in between preschool boys and girls in their intellectual ability level. These differences can be linked with the biological and social factors in between preschool boys and girls.

Biologically, both boys and girls will have different size of brain that might cause differences in their intellectual ability. As the present study found that preschool girls performed higher intellectual ability than preschool boys. It was contradicted with the previous research done by Ankey (1992) statement cited in Colom, Juan-Espinosa, Abad, and García (2000) that brain size is positively correlated with IQ, where on average males were found to have larger brains than females; and therefore males were expected to have a higher average level of IQ than females. This is reflected in brain size in between boys and girls do not contributed to the differences of intellectual level. One plausible explanation is that, instead of the brain size factor, more recent research on intelligence has shown that the thickness of cortical areas of the brain in children aged 6 to 18 years old were found more positively correlated with intellectual ability (Bjorklund, 2012). This indicated not all preschool boys born with bigger sizes of brain will performed higher intellectual ability than preschool girls, but this discrepancy can be explained as the fact that girls have overall faster development in 
intellectual ability during the pre-pubertal stage and advanced over the boys in the first 4-years of life in most cognitive domains (Toivainen, Papageorgiou, Tosto \& Kovas, 2017).

The other explanation for the discrepancy of intellectual ability between preschool boys and preschool girls could be linked to the social factor. Boys were known to be more active and preferred bigger group socialization compared to girls who were more sedentary and preferred smaller group socialization. This could be explained that the preschool settings in the present study were more boys and less girls settings, where the sex composition had no effects on girls but it was proved that to be worse development for boys (Moller, Forbes-Jones, Hightower \& Friedman, 2008). It is suggested for preschool classroom setting to be more balance in the number of boys and girls, perhaps to be half number of each sex to avoid from more boys and less girls setting that caused worse development for boys. In addition, boys and girls have to be arranged to mix together in their learning group to further improved their socialization in the classroom setting.

The present study concluded that there are differences in intellectual ability between preschool boys and girls, although some research (e.g., Pezzuti \& Orsini, 2016) found no differences between males and females in the intellectual ability. By understanding the impact of the intellectual ability in the childhood and preschool years, finding of present study provided important implication for those who work with parents and children, especially the school authorities such as the principals and teachers to avoid from bias or sex stereotyped on boys and girls. They must take note of the differences between boys' and girls' biology and social development where lesson plans in the classroom must be planned according to each sex interest and learning pace which can help to enforce both child's sex learning and development. Besides, other experts such as researchers or psychologists in the field of investigating children's intellectual ability are to ascertain and investigate further how children's intellectual ability is affected by parents (e.g., parenting styles or parental involvement), and to establish effective intervention approaches that can stimulate young children's intellectual ability.

\section{References}

Bian, L., Leslie, S.-J., \& Cimpian, A. (2017). Gender stereotypes about intellectual ability emerge early and influence children's interests. Science, 355(6323), 389-391. http://doi.org/10.1126/science.aah6524

Bruce, T. (2006). Early childhood: A guide for students. London: SAGE Publications.

Bukatko, D., \& Daehler, M. W. (2012). Child development: A thematic approach (6th ed.). USA: Wadsworth.

Bjorklund, D. F., \& Blasi, C, H. (2012). Child \& adolescent development: An integrated approach. USA: Wadsworth.

Calvin, C. M., Fernandes, C., Smith, P., Visscher, P. M., \& Deary, I. J. (2010). Sex, intelligence and educational achievement in a national cohort of over 175,000 11-year-old schoolchildren in England. Intelligence, 38(4), 424-432. https://doi.org/10.1016/j.intell.2010.04.005

Colom, R., Juan-Espinosa, M., Abad, F., \& García, L. F. (2000). Negligible sex differences in general intelligence. Intelligence, 28(1), 57-68. https://doi.org/10.1016/S01602896(99)00035-5

Deaux, K. (1985). Sex and gender. Annu. Rev. Psychol. 36, (49-81)

De Graaf, N. D., De Graaf, P. M., \& Kraaykamp, G. 2000). Parental cultural capital and educational attainment in the Netherlands: A refinement of the cultural capital perspective. Sociology of Education, 73(2), 92-111. 
Feingold, A. (1988). Cognitive gender differences are disappearing. American Psychologist, 43, 95-103.

Flavell, J. H. (1999). Cognitive development: Children's knowledge about the mind. Annual Review of Psychology, 50, 21-45.

Flynn, J. R., \& Shayer, M. (2018). IQ decline and Piaget: Does the rot start at the top? Intelligence, 66, 112-121. http://doi.org/10.1016/j.intell.2017.11.010

Harewood, T., Vallotton, C. D., \& Brophy-herb, H. (2016). More than just the breadwinner: The effects of fathers' parenting stress on children's language and cognitive development. Infant and Child Development, 1-19. https://doi.org/10.1002/icd

Heckman, J. J., \& Mosso, S. (2014). The economics of human development and social mobility. Annual Review of Economics, 6, 689-733.

Hedges, L. V., \& Friedman, L. (1993). Gender Differences in Variability in Intellectual Abilities: A Reanalysis of Feingold's Results. Review of Educational Research, 63(1), 94-105. http://doi.org/10.3102/00346543063001094

Huang, G., Xie, Y., \& Xu, H. (2015). Cognitive ability: Social correlates and consequences in contemporary China. Chinese Sociological Review, 47(4), 287-313. http://doi.org/10.1080/21620555.2015.1032161

Hyde, J. S., Fennema, E., \& Lamon, S. J. (1990). Gender differences in mathematics performance: A meta-analysis. Psychological Bulletin, 107, 139-153.

Hyde, J. S. (2016). Sex and cognition: Gender and cognitive functions. Current Opinion in Neurobiology, 38, 53-56. https://doi.org/10.1016/j.conb.2016.02.007

Kimball, M. M. (1989). A new perspective on women's math achievement. Psychological Bulletin, 105, 198-214.

Kleinfeld, J. (1998). The Myth that Schools Shortchange Girls: Social Science in the Service of Deception. The Women's Freedom Network, Washington, DC.

Marks, G. N. (2013). Education, social background and cognitive ability: The decline of the Social. New York: Taylor and Francis.

Moller, A. C., Forbes-Jones, E., Hightower, A. D., \& Friedman, R. (2008). The developmental influence of sex composition in preschool classrooms: Boys fare worse in preschool classrooms with more boys. Early Childhood Research Quarterly, 23(3), 409-418. http://doi.org/10.1016/j.ecresq.2008.05.001

Nisbett, R. E., Aronson, J., Blair, C., Dickens, W., Flynn, J., Halpern, D. F., \& Turkheimer, E. (2012). Intelligence: New findings and theoretical developments. American Psychologist, 67(2), 130-159.

Pallant, J. (2010). SPSS survival manual: A step by step guide to data analysis using SPSS. (4th ed.). UK: McGraw-Hill.

Pezzuti, L., \& Orsini, A. (2016). Are there sex differences in the Wechsler Intelligence Scale for Children - Forth Edition? Learning and Individual Differences, 45, 307-312. https://doi.org/10.1016/j.lindif.2015.12.024

Powell, P. J. (2010). The messiness of readiness. Phi Delta Kappan, 92(3), 26-28. Retrieved from http://journals.sagepub.com/doi/pdf/10.1177/003172171009200307

Reynolds, C. R., \& Hickman, J. A. (2004). Draw-a-person intellectual ability tests for children, adolescents, and adults. Texas: PRO-ED.

Rindermann, H., Sailer, M., \& Thompson, J. (2009). The impact of smart fractions, cognitive ability of politician a d average competence of peoples on social development. Talent Development \& Excellence, 1(1), 3-25.

Safer, D. J. (1986). Planning and administration nonpromotion correlates and outcomes at different grade levels. Journal of Learning Disabilities, 19(8), 500-503.

Stanley, J. C, Benbow, C. P., Brody, L. E., Dauber, S., \& Lupkowski, A. E. (1991). Gender differences in eighty-six nationally standardized aptitude and achievement tests. In 
N.Colangelo, S. G. Assouline, \& D. Ambroson (Eds.), National research symposium on talent development , 41-61. Iowa City: University of Iowa Pres

Strand, S., Deary, I. J., \& Smith, P. (2006). Sex differences in Cognitive Abilities Test scores: A UK national picture. British Journal of Educational Psychology, 76(3), 463-480. https://doi.org/10.1348/000709905X50906

Toivainen, T., Papageorgiou, K. A., Tosto, M. G., \& Kovas, Y. (2017). Sex differences in nonverbal and verbal abilities in childhood and adolescence. Intelligence, 64(July), 81-88. https://doi.org/10.1016/j.intell.2017.07.007

Wentzel, K. R., \& Erdley, C. A. (1993). Strategies for making friends: Relations to social behavior and peer acceptance in early adolescence. Developmental Psychology, 29(5), 819-826. 